\title{
Septicemia and mortality after noncardiac surgery associated with CHA2DS2-VASC score: a retrospective cohort study based on a real-world database
}

\author{
Li-Chin Sung 1,2,3, Chih-Chung Liü4,5,6, Chao-Shun Lin ${ }^{4,5,6}$, Chun-Chieh Yeh ${ }^{7,8}$, Yih-Giun Cherng ${ }^{6,9 \dagger}$, \\ Ta-Liang Chen ${ }^{5,6,10}$ and Chien-Chang Liao $4,5,6,11,12^{*}+$ (i)
}

\begin{abstract}
Background: Little was know about the association between the CHA2DS2-VASc score and postoperative outcomes. Our purpose is to evaluate the effects of CHA2DS2-VASc score on the perioperative outcomes in patients with atrial fibrillation (AF).

Methods: We identified 47,402 patients with AF over the age of 20 years who underwent noncardiac surgeries between 2008 and 2013 from claims data of the National Health Insurance in Taiwan. The CHA2DS2-VASc score was used to evaluate postoperative complications, mortality and the consumption of medical resources by calculating adjusted odds ratios (ORs) and 95\% confidence intervals (Cls).

Results: Compared with patients with a CHA2DS2-VASc score of 0, patients with scores $\geq 5$ had an increased risk of postoperative septicemia (OR 2.76, 95\% Cl 2.00-3.80), intensive care (OR 2.55, 95\% Cl 2.12-3.06), and mortality (OR $2.04,95 \% \mathrm{Cl} 1.14-3.64)$. There was a significant positive correlation between risk of postoperative complication and the CHA2DS2-VASC score $(P<0.0001)$.

Conclusion: The CHA2DS2-VASc score was highly associated with postoperative septicemia, intensive care, and 30-day mortality among AF patients. Cardiologists and surgical care teams may consider using the CHA2DS2-VASC score to evaluate perioperative outcome risks in patients with AF.
\end{abstract}

Keywords: Atrial fibrillation, CHA2DS2-VASc score, Infectious complications, Mortality, Surgery

\section{Background}

Atrial fibrillation (AF) is the most common sustained cardiac arrhythmia with an estimated five million incident cases worldwide [1, 2]. The 2010 global burden of disease study reported that there were 33.5 million patients with AF globally, constituting approximately $0.5 \%$ of the

*Correspondence: jacky48863027@yahoo.com.tw; ccliao@tmu.edu.tw ${ }^{\dagger}$ Yih-Giun Cherng and Chien-Chang Liao contribute equally to this work

${ }^{4}$ Department of Anesthesiology, Taipei Medical University Hospital,

Taipei, Taiwan

Full list of author information is available at the end of the article total world population [2]. The incidence of AF increases dramatically with age and is higher in men than women [3]. Numerous studies have reported a lifetime risk of developing AF among those aged $\geq 40$ years of approximately $20-25 \%$ [3]. Furthermore, this prevalence is likely underestimated since a large number of asymptomatic individuals and those having transient symptoms remain undiagnosed. AF is associated with an increased risk of thromboembolic stroke, acute coronary syndrome, heart failure, chronic kidney disease, hospitalization and 
all-cause mortality, as well as higher medical costs and a reduced quality of life $[1,4-6]$.

The CHA2DS2-VASc score for stroke risk assessment in patients with AF is well validated and has been widely applied and adopted in the U.S. and European clinical guidelines, as well as in the Asia Pacific Heart Rhythm Society, as a basic risk assessment tool [7-11]. The CHA2DS2-VASc score may predict adverse cardiovascular events and mortality in subsets of certain populations with high accuracy [12-14]. Moreover, the CHA2DS2VASc score has also been shown to be useful in predicting ischemic stroke even among individuals without $\mathrm{AF}$ $[12,15]$.

Since the number of people with AF is increasing, more AF patients will require risk stratification before surgery $[1,2]$. Clinical guidelines for perioperative risk assessment focus on coronary artery disease rather than AF as an important risk factor for adverse outcomes [16, 17]. In a population-based data analysis of 38,047 consecutive patients, the 30 -day postoperative mortality rate was significantly higher in patients with AF than in those with coronary heart disease [18]. Infectious complications are the major causes of postoperative morbidity and mortality in noncardiac surgery, which merits increased attention and intervention [19]. Some studies have also reported that $\mathrm{AF}$ is strongly associated with hospital-acquired pneumonia or postoperative infection [20]. However, limited information is available regarding the potential application of the CHA2DS2-VASc score to adverse outcomes in AF patients receiving noncardiac surgeries. Thus, we used reimbursement claims from the Taiwan Health Insurance Research Database to conduct a population-based cohort study to investigate whether the CHA2DS2-VASc score is associated with the relative risk of postoperative adverse events in patients with AF when receiving noncardiac surgeries.

\section{Methods}

\section{Source of data}

In this study, we used the Taiwan Health Insurance Research Database from the National Health Insurance in Taiwan, which was has been in place since 1995 and covers more than $99 \%$ of all residents. Basic patient characteristics, physician diagnoses, treatment procedures, medications, and consumption of medical resources were recorded in the database. Detailed information described in previous reports and articles based on this database was assessed scientifically and published in important journals $[21,22]$.

The data underlying this study is from the Health and Welfare Data Science Center, Department of Statistics, Ministry of Health and Welfare, Taiwan. Interested researchers can obtain the data through formal application to the Health and Welfare Data Science Center (http://dep.mohw.gov.tw/DOS/np-2497-113. html) and contact the agency with email. We have made the formal application (included application documents, study proposals, and ethics approval of the institutional review board) of the current insurance data. The authors of the present study had no special access privileges in accessing the data which other interested researchers would not have.

Under the regulations from the National Health Insurance In accordance with the Helsinki Declaration and in order to protect personal privacy, patient identifications were scrambled and decoded. Our study was evaluated and approved by the Institutional Review Board of Taipei Medical University (TMU-JIRB-201905042; TMU-JIRB-201902053; TMU-JIRB-201808012; TMU-JIRB-201710033; TMUJIRB-201701050; TMU-JIRB-201506001) and was exempted from the requirement for informed patient consent.

\section{Study design}

In the research database of the National Health Insurance, we identified $3,639,792$ patients aged $\geq 20$ years who underwent major surgeries (requiring general anesthesia or neuraxial anesthesia with hospitalization for more than one day) in 2008-2013. Of these, 47,402 had a history of AF assessed by the CHA2DS2-VASc score and categorized with scores of 0 and $\geq 5$. We analyzed postoperative infection-related complications, mortality, and consumption of medical resources among AF patients with various CHA2DS2-VASc scores.

\section{Criteria and definition}

The components of the CHA2DS2-VASc score included the following: age $\geq 75$ years ( 2 points), stroke/transient ischemic attack/thromboembolic event ( 2 points), age 65-74 years ( 1 point), female sex (1 point), congestive heart failure (1 point), hypertension ( 1 point), diabetes ( 1 point), and vascular disease (1 point). Low income is defined as individuals who utilize medical care services without paying the Taiwanese National Health Insurance copayment.

We used the International Classification of Diseases, Ninth Revision, Clinical Modification (ICD-9-CM) and administration codes to identify physician diagnoses of disease histories and complications after surgery in the Taiwan Health Insurance Research Database. Based on our previous studies, we included surgical patients' current medical conditions and their history of diseases such as mental disorders, chronic obstructive pulmonary disease, cancer, chronic kidney disease, hyperlipidemia, renal dialysis, Parkinson's disease, and liver cirrhosis as covariates in this study. Postoperative infection-related complications, such as pneumonia, septicemia, and 
urinary tract infection, were also identified. During the index surgical hospitalization, the consumption of medical resources including admission to an intensive care unit, length of hospital stay, and medical expenditure were also considered as study outcomes. In this study, we defined the postoperative adverse events as surgical patients has any of one complications or mortality during the index surgical hospitalization included postoperative pneumonia, septicemia, urinary tract infection, and 30-day in-hospital mortality.

\section{Statistical analysis}

We used chi-square tests to compare categorical variables (summarized using frequency and percentage) between AF patients with a CHA2DS2-VASc score of 0 and $\geq 1$. Continuous variables were compared using a $t$-test (summarized using mean $\pm \mathrm{SD}$ ). We used multivariate logistic regression to calculate the odds ratios (ORs) and $95 \%$ confidence intervals (CIs) of the CHA2DS2VASc score associated with postoperative pneumonia, septicemia, urinary tract infection, intensive care unit stay, and in-hospital mortality. Multiple linear regressions were used to evaluate the relationship between the CHA2DS2-VASc score and length of hospital stay and medical expenditure. Adjusted ORs (95\% CIs) of postoperative adverse events for patients with each component of the CHA2DS2-VASc score were also calculated. Multiple logistic regressions were also used to calculate adjusted ORs (95\% CIs) of the CHA2DS2-VASc score associated with postoperative adverse events in the subgroups of male gender, number of medical conditions and types of anesthesia.

\section{Results}

Among 47,402 surgical patients with AF (Additional file 1: Table S1), 45,639 (96.3\%) had a CHA2DS2VASc score of $\geq 1$. Compared with AF patients with a CHA2DS2-VASc score of 0 (Table 1), those with score of $\geq 1$ had higher incidences of mental disorders $(P<0.0001)$, liver cirrhosis $(P<0.0001)$, chronic obstructive pulmonary disease $(P<0.0001)$, stroke $(P<0.0001)$, chronic kidney disease $(P=0.003)$, and Parkinson's disease $(P<0.0001)$. The incidence of low income was higher in AF patients with scores of 0 compared with AF patients with scores of $\geq 1(P=0.0004)$.

Postoperative infection-related complications, such as pneumonia $(P<0.0001)$, septicemia $(P<0.0001)$, and urinary tract infection $(P<0.0001)$ were associated with the CHA2DS2-VASc score with a biological gradient trend. Compared to AF patients with a CHA2DS2-VASc score of 0 (Table 2), those with scores of $\geq 5$ showed an increased risk of postoperative pneumonia septicemia $(\mathrm{OR}=2.76 ; 95 \% \mathrm{CI} 2.00-3.80)$, intensive care $(\mathrm{OR}=2.55$;
Table 1 Characteristics of surgical patients with atrial fibrillation by CHA2DS2-VASc score

\begin{tabular}{|c|c|c|c|c|c|}
\hline & \multicolumn{2}{|c|}{$\begin{array}{l}0 \text { score } \\
(\mathrm{N}=1763)\end{array}$} & \multicolumn{2}{|c|}{$\begin{array}{l}\geq 1 \text { score } \\
(\mathrm{N}=45,639)\end{array}$} & \multirow[t]{2}{*}{$p$-value } \\
\hline & $\mathbf{n}$ & $(\%)$ & $\mathrm{n}$ & (\%) & \\
\hline \multicolumn{6}{|l|}{ Sex } \\
\hline Female & 0 & $(0.0)$ & 19,644 & $(43.0)$ & $<0.0001$ \\
\hline Male & 1763 & $(100.0)$ & 25,995 & $(57.0)$ & \\
\hline \multicolumn{6}{|l|}{ Age, years } \\
\hline $20-34$ & 69 & (3.9) & 148 & $(0.3)$ & $<0.0001$ \\
\hline $35-44$ & 158 & $(9.0)$ & 438 & $(1.0)$ & \\
\hline $45-54$ & 482 & $(27.3)$ & 1834 & $(4.0)$ & \\
\hline $55-64$ & 1054 & (59.8) & 5678 & $(12.4)$ & \\
\hline $65-74$ & 0 & $(0.0)$ & 12,622 & $(27.7)$ & \\
\hline$\geq 75$ & 0 & $(0.0)$ & 24,919 & $(54.6)$ & \\
\hline \multicolumn{6}{|l|}{ Low income } \\
\hline No & 1709 & $(96.9)$ & 44,402 & $(97.3)$ & 0.3722 \\
\hline Yes & 54 & $(3.1)$ & 1237 & $(2.7)$ & \\
\hline \multicolumn{6}{|l|}{ Medical conditions } \\
\hline Mental disorders & 313 & $(17.8)$ & 10,719 & $(23.5)$ & $<0.0001$ \\
\hline COPD & 110 & $(6.2)$ & 8887 & $(19.5)$ & $<0.0001$ \\
\hline Cancer & 280 & $(15.9)$ & 7648 & $(16.8)$ & 0.3337 \\
\hline Stroke & 0 & $(0.0)$ & 6865 & $(15.0)$ & $<0.0001$ \\
\hline CKD & 79 & $(4.5)$ & 3973 & $(8.7)$ & $<0.0001$ \\
\hline Hyperlipidemia & 70 & $(4.0)$ & 2206 & $(4.8)$ & 0.0963 \\
\hline Renal dialysis & 62 & $(3.5)$ & 2200 & $(4.8)$ & 0.0117 \\
\hline Parkinson's disease & 7 & $(0.4)$ & 1877 & $(4.1)$ & $<0.0001$ \\
\hline Liver cirrhosis & 85 & $(4.8)$ & 1359 & $(3.0)$ & $<0.0001$ \\
\hline Obesity & 10 & $(0.6)$ & 312 & $(0.7)$ & 0.5593 \\
\hline \multicolumn{6}{|l|}{ Types of surgery } \\
\hline Skin & 41 & $(2.3)$ & 1063 & $(2.3)$ & $<0.0001$ \\
\hline Breast & 1 & $(0.1)$ & 333 & $(0.7)$ & \\
\hline Musculoskeletal & 402 & $(22.8)$ & 15,119 & $(33.1)$ & \\
\hline Respiratory & 144 & $(8.2)$ & 1988 & $(4.4)$ & \\
\hline Digestive & 607 & $(34.4)$ & 12,173 & $(26.7)$ & \\
\hline Kidney, ureter, bladder & 169 & $(9.6)$ & 4216 & $(9.2)$ & \\
\hline Delivery, CS, abortion & 0 & $(0.0)$ & 59 & $(0.1)$ & \\
\hline Neurosurgery & 221 & $(12.5)$ & 6068 & $(13.3)$ & \\
\hline Eye & 20 & $(1.1)$ & 441 & $(1.0)$ & \\
\hline Others & 158 & $(9.0)$ & 4179 & $(9.2)$ & \\
\hline \multicolumn{6}{|l|}{ Types of anesthesia } \\
\hline General & 1360 & $(77.1)$ & 31,836 & $(69.8)$ & $<0.0001$ \\
\hline Epidural or Spinal & 403 & $(22.9)$ & 13,803 & $(30.2)$ & \\
\hline
\end{tabular}

$A F$ atrial fibrillation

95\% CI 2.12-3.06) and in-hospital mortality $(\mathrm{OR}=2.04$; 95\% CI 1.14-3.64) with significant trends ( $P$ for trend were $<0.0001$ for both). In Table 3, CHA2DS2-VASc score $\geq 5$ was associated with postoperative adverse events in patients received musculoskeletal surgery 
Table 2 Adverse outcomes after non-cardiac surgeries associated with CHA2DS2-VASc score in patients with atrial fibrillation

\begin{tabular}{|c|c|c|c|c|c|}
\hline \multirow[t]{2}{*}{ Postoperative outcomes } & \multirow[t]{2}{*}{ Scores } & \multirow[t]{2}{*}{$\mathbf{N}$} & \multicolumn{3}{|c|}{ Risk of outcome } \\
\hline & & & Events & Incidence, $\%$ & OR $(95 \% \mathrm{CI})^{\dagger}$ \\
\hline \multirow[t]{6}{*}{ Pneumonia } & 0 & 1763 & 56 & 3.2 & 1.00 (reference) \\
\hline & 1 & 7214 & 408 & 5.7 & $1.22(0.90-1.66)$ \\
\hline & 2 & 12,419 & 857 & 6.9 & $1.24(0.91-1.69)$ \\
\hline & 3 & 12,894 & 889 & 6.9 & $1.15(0.84-1.58)$ \\
\hline & 4 & 8314 & 699 & 8.4 & $1.30(0.94-1.79)$ \\
\hline & $\geq 5$ & 4798 & 435 & 9.1 & $1.31(0.94-1.83)$ \\
\hline \multirow[t]{6}{*}{ Septicemia } & 0 & 1763 & 55 & 3.1 & 1.00 (reference) \\
\hline & 1 & 7214 & 471 & 6.5 & $1.92(1.43-2.58)$ \\
\hline & 2 & 12,419 & 950 & 7.7 & $2.07(1.54-2.79)$ \\
\hline & 3 & 12,894 & 1071 & 8.3 & $2.19(1.62-2.95)$ \\
\hline & 4 & 8314 & 836 & 10.1 & $2.53(1.86-3.44)$ \\
\hline & $\geq 5$ & 4798 & 556 & 11.6 & $2.76(2.00-3.80)$ \\
\hline \multirow[t]{6}{*}{ Urinary tract infection } & 0 & 1763 & 57 & 3.2 & 1.00 (reference) \\
\hline & 1 & 7214 & 500 & 6.9 & $1.29(0.96-1.73)$ \\
\hline & 2 & 12,419 & 991 & 8.0 & $1.22(0.90-1.64)$ \\
\hline & 3 & 12,894 & 1197 & 9.3 & $1.30(0.96-1.76)$ \\
\hline & 4 & 8314 & 825 & 9.9 & $1.29(0.94-1.76)$ \\
\hline & $\geq 5$ & 4798 & 523 & 10.9 & $1.36(0.98-1.88)$ \\
\hline \multirow[t]{6}{*}{ Infectious complications* } & 0 & 1763 & 148 & 8.4 & 1.00 (reference) \\
\hline & 1 & 7214 & 1160 & 16.1 & $1.50(1.24-1.82)$ \\
\hline & 2 & 12,419 & 2340 & 18.8 & $1.56(1.29-1.89)$ \\
\hline & 3 & 12,894 & 2612 & 20.3 & $1.61(1.32-1.96)$ \\
\hline & 4 & 8314 & 1892 & 22.8 & $1.73(1.42-2.12)$ \\
\hline & $\geq 5$ & 4798 & 1237 & 25.8 & $1.93(1.56-2.38)$ \\
\hline \multirow[t]{6}{*}{ Intensive care } & 0 & 1763 & 254 & 14.4 & 1.00 (reference) \\
\hline & 1 & 7214 & 1485 & 20.6 & $1.38(1.18-1.61)$ \\
\hline & 2 & 12,419 & 3047 & 24.5 & $1.55(1.32-1.82)$ \\
\hline & 3 & 12,894 & 3412 & 26.5 & $1.67(1.42-1.97)$ \\
\hline & 4 & 8314 & 2659 & 32.0 & $2.15(1.81-2.55)$ \\
\hline & $\geq 5$ & 4798 & 1715 & 35.7 & $2.55(2.12-3.06)$ \\
\hline \multirow[t]{6}{*}{ 30-day in-hospital mortality } & 0 & 1763 & 18 & 1.0 & 1.00 (reference) \\
\hline & 1 & 7214 & 88 & 1.2 & $1.08(0.64-1.85)$ \\
\hline & 2 & 12,419 & 241 & 1.9 & $1.57(0.93-2.66)$ \\
\hline & 3 & 12,894 & 246 & 1.9 & $1.55(0.90-2.65)$ \\
\hline & 4 & 8314 & 195 & 2.4 & $1.87(1.08-3.25)$ \\
\hline & $\geq 5$ & 4798 & 121 & 2.5 & $2.04(1.14-3.64)$ \\
\hline
\end{tabular}

Cl confidence interval, $O R$ odds ratio

*Infectious complications included with pneumonia, septicemia, and urinary tract infection

${ }^{\dagger}$ Adjusted for all covariates listed in Table 1

$(\mathrm{OR}=4.40 ; 95 \% \mathrm{CI} 2.30-7.09)$ and digestive surgery $(\mathrm{OR}=1.67 ; 95 \%$ CI $1.14-2.45)$.

Compared to individuals with a CHA2DS2-VASc score of 0 (Table 4), patients aged $\geq 75$ years $(\mathrm{OR}=3.53$; 95\% CI 2.98-4.18) had the highest risk of postoperative adverse events followed by those with stroke $(\mathrm{OR}=2.14$; $95 \%$ CI $1.78-2.58)$, an age of $65-74$ years $(\mathrm{OR}=2.13$; $95 \%$
CI 1.79-2.52), congestive heart failure $(\mathrm{OR}=1.93 ; 95 \%$ CI 1.60-2.31), vascular disease (OR $=1.51$; 95\% CI 1.26 $1.81)$, diabetes $(\mathrm{OR}=1.82 ; 95 \%$ CI $1.51-2.18)$, female gender $(\mathrm{OR}=1.62$; 95\% CI 1.35-1.94), and hypertension $(\mathrm{OR}=1.53$; 95\% CI 1.28-1.84). The adjusted ORs of postoperative adverse events associated with CHA2DS2VASc score of $1,2,3,4, \geq 5$ were 1.47 (95\% CI 1.22-1.76), 
Table 3 Stratified analysis for risk of postoperative adverse events associated with CHA2DS2-VASc score in patients with atrial fibrillation

\begin{tabular}{|c|c|c|c|c|c|}
\hline & \multirow[t]{2}{*}{ Scores } & \multirow[t]{2}{*}{$\mathbf{N}$} & \multicolumn{3}{|c|}{ Postoperative adverse events* } \\
\hline & & & Events & Incidence, $\%$ & OR $(95 \% \mathrm{Cl})^{\dagger}$ \\
\hline \multirow[t]{6}{*}{ Musculoskeletal surgery } & 0 & 402 & 16 & 4.0 & 1.00 (reference) \\
\hline & 1 & 1662 & 201 & 12.1 & $2.43(1.41-4.19)$ \\
\hline & 2 & 3550 & 500 & 14.1 & $2.57(1.49-4.43)$ \\
\hline & 3 & 4527 & 742 & 16.4 & $3.07(1.78-5.32)$ \\
\hline & 4 & 3286 & 613 & 18.7 & $3.42(1.96-5.94)$ \\
\hline & $\geq 5$ & 2094 & 464 & 22.2 & $4.04(2.30-7.09)$ \\
\hline \multirow[t]{6}{*}{ Digestive surgery } & 0 & 607 & 47 & 7.7 & 1.00 (reference) \\
\hline & 1 & 2259 & 342 & 15.1 & $1.39(0.99-1.95)$ \\
\hline & 2 & 3633 & 729 & 20.1 & $1.58(1.12-2.22)$ \\
\hline & 3 & 3366 & 754 & 22.4 & $1.51(1.07-2.14)$ \\
\hline & 4 & 1887 & 492 & 26.1 & $1.54(1.07-2.21)$ \\
\hline & $\geq 5$ & 1028 & 315 & 30.6 & $1.67(1.14-2.45)$ \\
\hline \multirow[t]{6}{*}{ Neurosurgery } & 0 & 221 & 41 & 18.6 & 1.00 (reference) \\
\hline & 1 & 843 & 165 & 19.6 & $0.87(0.59-1.29)$ \\
\hline & 2 & 1630 & 389 & 23.9 & $0.98(0.66-1.46)$ \\
\hline & 3 & 1773 & 429 & 24.2 & $0.94(0.63-1.42)$ \\
\hline & 4 & 1189 & 301 & 25.3 & $0.92(0.60-1.42)$ \\
\hline & $\geq 5$ & 633 & 184 & 29.1 & $1.05(0.66-1.67)$ \\
\hline \multirow[t]{6}{*}{ Respiratory surgery } & 0 & 144 & 15 & 10.4 & 1.00 (reference) \\
\hline & 1 & 399 & 104 & 26.1 & $1.54(0.82-2.88)$ \\
\hline & 2 & 546 & 182 & 33.3 & $1.52(0.80-2.87)$ \\
\hline & 3 & 480 & 191 & 39.8 & $1.65(0.85-3.19)$ \\
\hline & 4 & 348 & 157 & 45.1 & $1.94(0.98-3.85)$ \\
\hline & $\geq 5$ & 215 & 104 & 48.4 & $1.82(0.86-3.81)$ \\
\hline
\end{tabular}

Cl confidence interval, OR odds ratio

*Postoperative adverse events included with pneumonia, septicemia, urinary tract infection, and 30-day in-hospital mortality

${ }^{\dagger}$ Adjusted for all covariates listed in Table 1

1.55, (95\% CI 1.29-1.87), 1.62 (95\% CI 1.33-1.95), 1.74 (95\% CI 1.44-2.12), and 1.96 (95\% CI 1.60-2.41), respectively.

In Additional file 1: Table S2, the average hospital stay length $(P<0.0001)$ and medical expenditure $(P<0.0001)$ were higher in surgical patients with a CHA2DS2VASc score of $\geq 5$ compared to surgical patients with a CHA2DS2-VASc score of 0 . After adjusting for covariates in the multiple regression analysis, the CHA2DS2-VASc score was significantly associated with the length of hospital stay (beta $=1.25, P<0.0001$ ) and medical expenditure (beta $=256, P<0.0001$ ).

Additional file 1: Table S3 shows a stratified analysis of the risk of postoperative adverse events in association with a CHA2DS2-VASc score in patients with AF. Among patients with AF, a CHA2DS2-VASc score of $\geq 4$ is a significant risk factor for adverse events after noncardiac surgeries in the following subgroups: male $(\mathrm{OR}=2.11 ; 95 \%$ CI $1.72-2.58)$, patients with 0 medical conditions $(\mathrm{OR}=2.49 ; 95 \% \mathrm{CI} 1.88-3.28)$, patients with 1 medical condition ( $\mathrm{OR}=1.79 ; 95 \% \mathrm{CI} 1.31-2.45)$, patients with $\geq 2$ medical conditions $(\mathrm{OR}=2.50$; $95 \% \mathrm{CI}$ 1.53-4.09), epidural/spinal anesthesia $(\mathrm{OR}=2.43 ; 95 \%$ CI 1.50-3.93), and general anesthesia $(\mathrm{OR}=2.06$; $95 \% \mathrm{CI}$ 1.67-2.54).

\section{Discussion}

This study is the first population-based study to report the application of the CHA2DS2-VASc score to assessments of perioperative of noncardiac surgery outcomes in patients with AF. The CHA2DS2-VASc score was highly associated with postoperative major infection, intensive care unit stay, and 30-day mortality. Prolonged length of hospital stay and elevated medical expenditures were also noted in patients with higher CHA2DS2-VASc scores. The biological gradient effects existed in the CHA2DS2VASc score associated with postoperative infections and 
Table 4 Adverse events after non-cardiac surgeries associated with components of CHA2DS2-VASc score

\begin{tabular}{|c|c|c|c|c|}
\hline \multirow[t]{2}{*}{ Components of CHA2DS2-VASc score } & \multirow[t]{2}{*}{$\mathrm{N}$} & \multicolumn{3}{|c|}{ Postoperative adverse events* } \\
\hline & & Events & Rate, \% & OR $(95 \% \mathrm{Cl})^{\dagger}$ \\
\hline Control group (0 score) & 1763 & 160 & 9.1 & 1.00 (reference) \\
\hline \multicolumn{5}{|l|}{ Patient with } \\
\hline Age $\geq 75$ years ( $\geq 2$ scores) & 24,919 & 6394 & 25.7 & $3.53(2.98-4.18)$ \\
\hline Stroke ( $\geq 2$ scores) & 6865 & 1949 & 28.4 & $2.14(1.78-2.58)$ \\
\hline Age $65-74$ years ( $\geq 1$ score) & 12,622 & 2215 & 17.6 & $2.13(1.79-2.52)$ \\
\hline Congestive heart failure ( $\geq 1$ score) & 11,232 & 2934 & 26.1 & $1.93(1.60-2.31)$ \\
\hline Vascular disease ( $\geq 1$ score) & 13,488 & 2871 & 21.3 & $1.51(1.26-1.81)$ \\
\hline Diabetes ( $\geq 1$ score) & 12,491 & 2930 & 23.5 & $1.82(1.51-2.18)$ \\
\hline Female ( $\geq 1$ score) & 19,644 & 3979 & 20.3 & $1.62(1.35-1.94)$ \\
\hline Hypertension ( $\geq 1$ score) & 27,894 & 5972 & 21.4 & $1.53(1.28-1.84)$ \\
\hline \multicolumn{5}{|l|}{ CHA2DS2-VASc score } \\
\hline 0 & 1763 & 160 & 9.1 & 1.00 (reference) \\
\hline 1 & 7214 & 1205 & 16.7 & $1.47(1.22-1.76)$ \\
\hline 2 & 12,419 & 2458 & 19.8 & 1.55 (1.29-1.87) \\
\hline 3 & 12,894 & 2750 & 21.3 & $1.61(1.33-1.95)$ \\
\hline 4 & 8314 & 1994 & 24.0 & $1.74(1.44-2.12)$ \\
\hline$\geq 5$ & 4798 & 1310 & 27.3 & $1.96(1.60-2.41)$ \\
\hline
\end{tabular}

Cl confidence interval, $O R$ odds ratio

*Postoperative adverse events included with pneumonia, septicemia, urinary tract infection, and mortality

${ }^{\dagger}$ Adjusted for all covariates listed in Table 1

mortality. The association between CHA2DS2-VASc score and postoperative adverse events remained significant for various subgroups.

Age, sex, and socioeconomic covariates commonly influence perioperative outcomes [23-25]. Postoperative complications are mainly determined by types of surgery and anesthesia, as well as pre-existing medical conditions such as hyperlipidemia, mental disorder, liver cirrhosis, renal disease, chronic obstructive pulmonary disease, Parkinson's disease and cancer. These conditions are also considered to be potential associated factors of postoperative complications and mortality [23, 26-31]. To avoid bias when investigating the relationships between the CHA2DS2-VASc score and postoperative outcomes, we used multivariate logistic regression models to adjust for these potential confounding factors. We then showed that the CHA2DS2-VASc score was a statistically significant predictor for postoperative infection and in-hospital mortality in patient with AF.

Recent studies have reported that preoperative $\mathrm{AF}$ clearly increases the risk of perioperative stroke and adverse cardiovascular events, as well as short-term and long-term mortality [18, 32, 33]. Whether various CHA2DS2-VASc scores are correlated with other postoperative complications in AF patients undergoing noncardiac surgeries remains unclear. According to the present data, incremental increases in CHA2DS2-VASc scores caused a two- to three-fold risk in infection-related postoperative complications. The possible explanation is that each component of the scoring systems was proven to be independently associated with higher risks of postoperative infection and mortality $[20,21,25,34-36]$. In our previous report and present investigation, patients with a previous stroke had double the risk of postoperative mortality than patients without previous stroke, either in the entire or AF populations [21]. Moreover, each of these factors has been independently recognized to affect outcomes in AF. The CHA2DS2-VASc score predicts stroke risk in AF patients and research has shown that up to $50 \%$ of patients who had acute stroke have clinical evidence of aspiration pneumonia or sepsis, demonstrating its predictive role for infectious outcomes [20,37]. On the basis of these findings, we postulate that the CHA2DS2-VASc score is strongly associated with postoperative complications in AF patients. However, this assumption should be validated in future prospective randomized trials.

Preoperative AF was independently associated with higher postoperative complications in patients undergoing noncardiac surgery [18]. In the current clinical settings, the Revised Cardiac Risk Index or the American College of Surgeons National Surgical Quality Improvement Program risk model calculator were used to assess the cardiovascular risk in all patients who were scheduled to undergo noncardiac surgeries [38]. 
According to the clinical practice guidelines, electrocardiogram and echocardiography are common tools for assessing perioperative outcomes that are not recognized as risks in aforementioned risk model calculators $[16,17,38]$. However, the comprehensive assessment of preoperative risk stratification in AF population has not been ideally established. Therefore, our study examined the possibility of applying the CHA2DS2-VASc score to surgical patients in order to assess infectious complications and mortality.

A retrospective population-based cohort study was conducted to investigate which risk score for perioperative outcomes prediction in patients with AF undergoing noncardiac surgery and concluded that the CHA2DS2VASc score provides acceptable preoperative risk stratification for major perioperative events including mortality [26]. Compared with our study, the authors did not adjust some possible potential confounding factors into their analysis (such as socioeconomic status, hyperlipidemia, liver cirrhosis and types of anesthesia). Additionally, the patient cohort in our study was larger and from a more recent time period compared with the previous cohort study [26]. Furthermore, the present study provides evidence that patients with AF with an increased CHA2DS2-VASc score have an increased risk for postoperative adverse events compared to patients with AF only. With these results, clinicians can precisely access the risk of adverse outcomes and allocate medical resources in AF patients with coexisting medical conditions when they undergo noncardiac surgeries.

This study had several inherent limitations. First, several unmeasured factors, such as the type of AF (paroxysmal or non-paroxysmal), frailty, various perioperative AF medication management strategies, drug compliance, alcohol consumption, body mass index, cigarette smoking, physical activity level, and perioperative heart rate status, were unavailable in our database. Failure to consider the aforementioned variables may have led to a certain degree of residual bias. However, considering the significance and magnitude of the observed effects, it is unlikely that these limitations compromised the results. Second, comorbidity severities (such as CHA2DS2-VASc score components) and coexisting medical conditions were defined by registered diagnosis codes, not by laboratory data, image studies or clinical evaluations. In addition, because the study cohort included only Taiwanese patients with $\mathrm{AF}$, the results may not be generalizable to other populations. Finally, our investigation was a retrospective observational study, which had certain methodological limitations. Understanding the causal inference between the CHA2DS2-VASc score and perioperative outcomes requires future prospective studies.

\section{Conclusions}

In conclusion, the CHA2DS2-VASc scoring system is an important independent predictor for postoperative septicemia, 30-day mortality, and consumption of medical resources in patients with AF undergoing noncardiac surgeries. Our study suggests that perioperative care teams could apply CHA2DS2-VASc scores preoperatively for AF patients receiving noncardiac surgeries. Future studies are needed to assess the application of CHA2DS2-VASc scores to AF patients undergoing noncardiac surgeries.

\section{Abbreviations \\ AF: Atrial fibrillation; ICD-9-CM: International code of diseases, ninth edition, clinical modification; OR: Odds ratio; Cl: Confidence interval.}

\section{Supplementary Information}

The online version contains supplementary material available at https://doi. org/10.1186/s12893-021-01209-z.

Additional file 1: Table S1. Characteristics of surgical patients with atrial fibrillation. Table S2. Length of hospital stay and medical expenditures associated with CHA2DS2-VASc score in patients with atrial fibrillation. Table S3. Stratified analysis for risk of postoperative adverse events associated with CHA2DS2-VASc score in patients with atrial fibrillation.

\section{Acknowledgements}

This study is based in part on data obtained from Taiwan's Ministry of Health and Welfare. The authors' interpretations and conclusions do not represent Taiwan's Ministry of Health and Welfare.

\section{Authors' contributions}

LCS, CC Liu, CSL, CCY, YGC, TLC, and CC Liao were involved in the conception and design of the work. TLC was involved in the data acquisition. CC Liao was involved in the data analysis. LCS, CC Liu, CSL, CCY, YGC, TLC, and CC Liao were involved in the interpretation of data for the work. LCS and CC Liao wrote the first draft of the manuscript. All authors were involved in drafting the work and revising it critically. The authors gave final approval of the version to be published. All authors read and approved the final manuscript.

\section{Funding}

This work was supported by Taiwan's Ministry of Science and Technology (MOST108-2221-E-038-006; MOST106-2314-B-038-036-MY3). The funder had no role in the design of the study and collection, analysis, and interpretation of data and in writing the manuscript.

\section{Declarations}

\section{Ethics approval and consent to participate}

According to the regulation from Taiwan's Ministry of Health and Welfare, our study was exempted from the requirement for informed patient consent because patient identifications were scrambled and decoded. Our study was evaluated and approved by the Institutional Review Board of Taipei Medical University (TMU-JRB-201905042; TMU-JIRB-201902053; TMU-JIRB-201808012; TMU-JIRB-201710033; TMU-JIRB-201701050; TMU-JIRB-201506001).

\section{Consent for publication}

Not applicable.

\section{Competing interests}

None to declare. 


\section{Author details}

${ }^{1}$ Division of Cardiology, Department of Internal Medicine, School of Medicine, College of Medicine, Taipei Medical University, Taipei City, Taiwan. ${ }^{2}$ Division of Cardiology, Department of Internal Medicine, Shuang Ho Hospital, Taipei Medical University, New Taipei City, Taiwan. ${ }^{3}$ Taipei Heart Institute, Taipei Medical University, Taipei, Taiwan. ${ }^{4}$ Department of Anesthesiology, Taipei Medical University Hospital, Taipei, Taiwan. ${ }^{5}$ Anesthesiology and Health Policy Research Center, Taipei Medical University Hospital, Taipei, Taiwan. ${ }^{6}$ Department of Anesthesiology, School of Medicine, College of Medicine, Taipei Medical University, Taipei, Taiwan. ${ }^{7}$ Department of Surgery, China Medical University Hospital, Taichung, Taiwan. ${ }^{8}$ Department of Surgery, University of Illinois, Chicago, USA. ${ }^{9}$ Department of Anesthesiology, Shuang Ho Hospital, Taipei Medical University, New Taipei City, Taiwan. ${ }^{10}$ Department of Anesthesiology, Wan Fang Hospital, Taipei Medical University, Taipei, Taiwan. ${ }^{11}$ Research Center of Big Data and Meta-Analysis, Wan Fang Hospital, Taipei Medical University, Taipei, Taiwan. ${ }^{12}$ School of Chinese Medicine, College of Chinese Medicine, China Medical University, Taichung, Taiwan.

Received: 14 October 2020 Accepted: 15 April 2021

Published online: 26 April 2021

\section{References}

1. Chugh SS, Roth GA, Gillum RF, Mensah GA. Global burden of atrial fibrillation in developed and developing nations. Glob Heart. 2014;9:113-9.

2. Chugh SS, Havmoeller R, Narayanan K, Singh D, Rienstra M, Benjamin EJ, et al. Worldwide epidemiology of atrial fibrillation: a Global Burden of Disease 2010 Study. Circulation. 2014;129:837-47.

3. Lloyd-Jones DM, Wang TJ, Leip EP, Larson MG, Levy D, Vasan RS, et al. Lifetime risk for development of atrial fibrillation: the Framingham Heart Study. Circulation. 2004;110:1042-6.

4. Chao TF, Lip GY, Liu CJ, Tuan TC, Chen SJ, Wang KL, et al. Validation of a modified CHA2DS2-VASc Score for stroke risk stratification in Asian patients with atrial fibrillation: a nationwide cohort study. Stroke. 2016;47:2462-9.

5. He W, Chu Y. Atrial fibrillation as a prognostic indicator of myocardial infarction and cardiovascular death: a systematic review and meta-analysis. Sci Rep. 2017;7:3360.

6. Shaver CM, Chen W, Janz DR, May AK, Darbar D, Bernard GR, et al. Atrial fibrillation is an independent predictor of mortality in critically ill patients. Crit Care Med. 2015:43:2104-11.

7. January CT, Wann LS, Alpert JS, Calkins H, Cigarroa JE, Cleveland JC Jr, et al. 2014 AHA/ACC/HRS guideline for the management of patients with atrial fibrillation: a report of the American College of Cardiology/American Heart Association Task Force on Practice Guidelines and the Heart Rhythm Society. J Am Coll Cardiol. 2014;64:e1-76.

8. Camm AJ, Lip GY, De Caterina R, Savelieva I, Atar D, Hohnloser SH, et al. 2012 focused update of the ESC Guidelines for the management of atrial fibrillation: an update of the 2010 ESC Guidelines for the management of atrial fibrillation. Developed with the special contribution of the European Heart Rhythm Association. Eur Heart J. 2012;33:2719-47.

9. Senoo K, Lane DA, Lip GY. Stroke risk reduction with oral anticoagulation using CHA2DS2-VASc in a Japanese AF population: a modeling analysis. Int J Cardiol. 2015;181:247-54

10. Chao TF, Liu CJ, Tuan TC, Chen SJ, Wang KL, Lin YJ, et al. Comparisons of CHADS2 and CHA2DS2-VASc scores for stroke risk stratification in atrial fibrillation: which scoring system should be used for Asians? Heart Rhythm. 2016;13:46-53.

11. Ogawa S, Aonuma K, Tse HF, Huang D, Huang JL, Kalman J, et al. The APHRS's 2013 statement on antithrombotic therapy of patients with nonvalvular atrial fibrillation. J Arrhythm. 2013;29:190-200.

12. Melgaard L, Gorst-Rasmussen A, Lane DA, Rasmussen LH, Larsen TB, Lip GY. Assessment of the CHA2DS2-VASc score in predicting ischemic stroke, thromboembolism, and death in patients with heart failure with and without atrial fibrillation. JAMA. 2015;314:1030.

13. Saliba W, Rennert G. CHA2DS2-VASc score is directly associated with the risk of pulmonary embolism in patients with atrial fibrillation. Am J Med. 2014; 127:45-52.

14. Cetin M, Cakici M, Zencir C, Tasolar H, Baysal E, Balli M, et al. Prediction of coronary artery disease severity using CHADS2 and CHA2DS2-VASC scores and a newly defined CHA2DS2-VASC-HS score. Am J Cardiol. 2014;113:950-6.

15. Mitchell LB, Southern DA, Galbraith D, Ghali WA, Knudtson M, Wilton SB, et al. Prediction of stroke or TIA in patients without atrial fibrillation using CHADS2 and CHA2DS2-VASc scores. Heart. 2014;100:1524-30.

16. Fleisher LA, Fleischmann KE, Auerbach AD, Barnason SA, Beckman JA, Bozkurt B, et al. 2014 ACC/AHA guideline on perioperative cardiovascular evaluation and management of patients undergoing noncardiac surgery: executive summary:a report of the American College of Cardiology/ American Heart Association Task Force on Practice Guidelines. Circulation. 2014;130:2215-45.

17. Kristensen SD, Knuuti J, Saraste A, Anker S, Bøtker HE, Hert SD, et al. 2014 ESC/ESA Guidelines on non-cardiac surgery: cardiovascular assessment and management: The Joint Task Force on non-cardiac surgery: cardiovascular assessment and management of the European Society of Cardiology (ESC) and the European Society of Anaesthesiology (ESA). Eur Heart J. 2014;35:2383-431.

18. van Diepen S, Bakal JA, McAlister FA, Ezekowitz JA. Mortality and readmission of patients with heart failure, atrial fibrillation, or coronary artery disease undergoing noncardiac surgery: an analysis of 38047 patients. Circulation. 2011;124:289-96.

19. Fernandez-Bustamante A, Frendl G, Sprung J, Kor DJ, Subramaniam B, Martinez Ruiz R, et al. Postoperative pulmonary complications, early mortality, and hospital stay following noncardiothoracic surgery: a multicenter study by the perioperative research network investigators. JAMA Surg. 2017;152:157-66.

20. Zhu J, Zhang X, Shi G, Yi K, Tan X. Atrial fibrillation is an independent risk factor for hospital-acquired pneumonia. PLoS ONE. 2015;10:e0131782.

21. Liao CC, Chang PY, Yeh CC, Hu CJ, Wu CH, Chen TL. Outcomes after surgery in patients with previous stroke. Br J Surg. 2014;101:1616-22.

22. Liao CC, Shen WW, Chang CC, Chang H, Chen TL. Surgical adverse outcomes in patients with schizophrenia: a population-based study. Ann Surg. 2013;257:433-8.

23. Dik VK, Aarts MJ, Van Grevenstein WM, Koopman M, Van Oijen MG, Lemmens VE, et al. Association between socioeconomic status, surgical treatment and mortality in patients with colorectal cancer. Br J Surg. 2014;101:1173-82.

24. Sabate S, Mases A, Guilera N, Canet J, Castillo J, Orrego C, et al. Incidence and predictors of major perioperative adverse cardiac and cerebrovascular events in non-cardiac surgery. Br J Anaesth. 2011;107:879-90.

25. Saxena A, Virk SA, Bowman S, Chan L, Jeremy R, Bannon PG. Preoperative atrial fibrillation portends poor outcomes after coronary bypass graft surgery: a systematic review and meta-analysis. J Thorac Cardiovasc Surg. 2018;155:1524-33.

26. van Diepen S, Youngson E, Ezekowitz JA, McAlister FA. Which risk score best predicts perioperative outcomes in nonvalvular atrial fibrillation patients undergoing noncardiac surgery? Am Heart J. 2014;168:60-7.

27. Gupta H, Ramanan B, Gupta PK, Fang X, Polich A, Modrykamien A, et al. Impact of COPD on postoperative outcomes: results from a national database. Chest. 2013;143:1599-606.

28. Drolet S, Maclean AR, Myers RP, Shaheen AA, Dixon E, Donald BW. Morbidity and mortality following colorectal surgery in patients with end-stage renal failure: a population-based study. Dis Colon Rectum. 2010;53:1508-16.

29. Pepper PV, Goldstein MK. Postoperative complications in Parkinson's disease. J Am Geriatr Soc. 1999;47:967-72.

30. Smetana GW, Lawrence VA, Cornell JE. Preoperative pulmonary risk stratification for noncardiothoracic surgery: systematic review for the American College of Physicians. Ann Intern Med. 2006;144:581-95.

31. Guay J, Choi PT, Suresh S, Albert N, Kopp S, Pace NL. Neuraxial anesthesia for the prevention of postoperative mortality and major morbidity: an overview of cochrane systematic reviews. Anesth Analg. 2014;119:716-25.

32. Al-Sarraf N, Thalib L, Hughes A, Tolan M, Young V, McGovern E. Effect of preoperative atrial fibrillation on postoperative outcome following cardiac surgery. Cardiol Res Pract. 2012;2012:272384.

33. Attaran S, Shaw M, Bond L, Pullan MD, Fabri BM. A comparison of outcome in patients with preoperative atrial fibrillation and patients in sinus rhythm. Ann Thorac Surg. 2011;92:1391-5.

34. Yeh CC, Liao CC, Chang YC, Jeng LB, Yang HR, Shih CC, et al. Adverse outcomes after noncardiac surgery in patients with diabetes: a 
nationwide population-based retrospective cohort study. Diabetes Care 2013;36:3216-21.

35. Simonsen DF, Søgaard M, Bozi I, Horsburgh CR, Thomsen RW. Risk factors for postoperative pneumonia after lung cancer surgery and impact of pneumonia on survival. Respir Med. 2015;109:1340-6.

36. Matz K, Seyfang L, Dachenhausen A, Teuschl Y, Tuomilehto J, Brainin M, et al. Post-stroke pneumonia at the stroke unit-a registry based analysis of contributing and protective factors. BMC Neurol. 2016;16:107.

37. Wartenberg KE, Stoll A, Funk A, Meyer A, Schmidt JM, Berrouschot J. Infection after acute ischemic stroke: risk factors, biomarkers, and outcome. Stroke Res Treat. 2011;2011:830614.
38. Cohn SL, Fernandez RN. Comparison of 4 cardiac risk calculators in predicting postoperative cardiac complications after noncardiac operations. Am J Cardiol. 2018:121:125-30.

\section{Publisher's Note}

Springer Nature remains neutral with regard to jurisdictional claims in published maps and institutional affiliations.
Ready to submit your research? Choose BMC and benefit from:

- fast, convenient online submission

- thorough peer review by experienced researchers in your field

- rapid publication on acceptance

- support for research data, including large and complex data types

- gold Open Access which fosters wider collaboration and increased citations

- maximum visibility for your research: over $100 \mathrm{M}$ website views per year

At BMC, research is always in progress.

Learn more biomedcentral.com/submissions 